\title{
Pitfalls in the quality management of cancer care
}

\begin{abstract}
There are a lot of pitfalls threatening the quality management of our patients. Conflicts of interest, overuse, underuse and misuse of diagnostic and treatment modalities can harm patients and are difficult to detect. A lot of confounding factors are present. It is very difficult to define the right standard, because it will depend on your personal point of view and the quality of the evidence based system. Quality measurements must integrate the different elements of care, looking at health care as a complex adaptive system. We must be aware of budget restrictions, bureaucracy and last but not least: The Human Factor, Fraud and Money!
\end{abstract}

Keywords: quality management. breast cancer, health care
Volume 3 Issue 3 - 2015

\author{
Didier Verhoeven, ${ }^{1,2}$ Christine Langenaeken ${ }^{2}$ \\ 'University of Antwerp, Belgium \\ ${ }^{2}$ Iridium cancer network, Belgium
}

Correspondence: Didier Verhoeven, University of Antwerp, Universiteitsplein I, 2610 Antwerp, Belgium, Tel 036505 I 57, Email Didier.verhoeven@klina.be

Received: October 29, 2015 | Published: November 05, 2015

\section{Editorial}

Quality Management is key for a better care of our cancer patients. In order to come to a better understanding of delivering quality cancer care some pitfalls have to be taken into account. Any publication nowadays is to end with the disclosure of conflicts of interest. We all have a lot of conflicts of interest, and probably we will forget the most important ones. We have personal interests, values and contacts with friendly pharmaceutical companies. Most of us work in a hospital where professional values and government policy may be contradictory. All these personal interests and values are the most important pitfalls of Quality Management!

Reflecting about quality of health care we are confronted whit a changing paradigm: from a basically ethical point of view to an economical one with management logic superimposed on a cultural background! Quality of care is a very complex process. When defining quality management we are confronted with an "ideal, humanistic approach" on the one hand, and the "real world" situation where budget restrictions have to be taken into account, on the other hand. ${ }^{1}$ What is ideal cannot always be given to patients. In the USA, society has long held the view that health care is a product to be paid for, as shown in the film Sicko by Michael Moore. In Europe, solidarity has traditionally played a major role in the organization and provision of health care. "Obamacare" tries to make things change. ${ }^{2}$

Quality is not just the right procedure: it is also the expertise of the individual delivering the care, setting the right indication, in other words: the right person, who does it the right way! The World Health Organization defined "Quality of Care" as a process of making strategic choices in the health care system. The most important factors are good leadership and teamwork, combined with a systematic way of improving the delivery of care.

The aim of quality indicators is to measure quality management. Quality Indicators can be divided into structural indicators related to the organization of the health care system and process indicators related to what is done, this being influenced by both patients and providers. In addition outcome indicators measure what happens to the patients' health as the end result of health care practices. ${ }^{3}$

Critical factors in health care management are the patient's safety. A correct diagnosis on the positive side, and failure of proven effectiveness of treatment and lack of patient-centeredness on the negative side. Overuse, underuse and misuse all threaten patient safety.
Failure to provide evidence based care threatens effectiveness. How to find your way in the large numbers of randomized controlled trials published every year? Patients' lack of confidence in the health care system may lowers their compliance with the prescribed medications and undermine the confidence they have in their treatment.

There are a lot of challenges and confounding factors when developing "high quality" indicators. They have to be defined correctly and must be calculated using accurate data sources. In addition we are confronted with a resistance to change and difficulties with self-assessment. In most cases organizations are not rewarded for acknowledging deficiencies..

Lord Kelvin made the following statement: "When you can measure what you are speaking about and express it in numbers you know something about it; but when you cannot express it in numbers your knowledge is of a meager and unsatisfactory kind". But is this the truth? Quality is much more than mere numbers! In addition there are important difficulties in trying to define the optimal standard. A good example is the study in the Netherlands about the use of preoperative diagnostic MRI as a function of the number of breast cancer patients who had surgery as their primary treatment. There is no correlation between the amount of patients per center and the use of MRI. How to interpret these results? Large inter-hospital variation may reflect any of the following: a different patient population, true differences in quality of care, lack of scientific evidence or lack of consensus regarding scientific evidence. Should the average become the standard? Who are the hospitals that organized health care in the most cost-effective way: the ones who performed over $70 \%$ or those who had 'only' $10 \%$ of preoperative MRI?. ${ }^{4}$

The introduction of a "Pay for Performance" or "Pay for Quality" system" is not a magic bullet! Short term advantages are not maintained, as was reported in the NEJM recently. ${ }^{5}$ The coupling of such systems with Quality indicators as proposed even negatively affected the quality of care. Physicians are tempted to play with the system to maximize their income, and public reporting changes their behavior. A large part of clinical practice cannot be measured. New indicators are needed for complex situations, although they will be increasing the administrative burden. There is an urgent need to reinvent quality measurements integrated with the delivery of care, to improve the measurements' performance, to address the challenges physicians are facing in everyday practice, and to reflect patients' preferences and treatment heterogeneity. 
The evaluation of current quality management systems points to a number of shortcomings. Systems have evolved into a system working as a function of what is measured, leading to a proliferation of measurements, and in whom appearance is more important than content. We have forgotten the core business i.e. the face of the patient, introducing an "institutionalized distrust", not apt to control the immeasurable: everybody is considered a thief.

Healthcare must be seen as a complex adaptive system, a dynamic process with multiple stakeholders. ${ }^{6}$ Such an approach takes into account that interactions of different components are simultaneously affected and shaped by the system, a system in which most often the buyer is not the payer (at least in a social security system). The advantage of this approach and hence its relevance to managing pitfalls in cancer management is the challenging of assumptions. It's about focusing on relationships rather than on simple 'cause and effect' models. This approach can be applied to a variety of contexts. It may provide a framework for analyzing knowledge and agents, and bringing up new ideas and opportunities for change. It will serve to provide a more complete picture of forces affecting change.

One of the important pitfalls and controversies with regard to quality management and control is the cost and discussion about proven return on investment. Last year the Rector-Chairman of the University of Leuven (Belgium), professor Rik Torfs issued a public statement about the quality control of the Belgian universities. In his opinion, control cost too much and there was practically no return on investment. Abolishing these audits would save two million euro's in Flanders only. According to professor Torfs the universities could control themselves. Some months later the government decided to suspend these audits.

Parkinson derived his law from his extensive experience in the British Civil Service, describing the rate at which bureaucracies expand over time. He observed an increase in the number of employees at the Colonial Office while Great Britain's overseas empire declined with a lack of colonies to administer. He explained this controversial growth by two factors: " An official wants to multiply subordinates, not rivals" and " "Officials make work for each other." He noted that the number employed in a bureaucracy rose by 5-7\% every year "irrespective of any variation in the amount of work to be done". So how can we preserve an optimal balance between our core business which is, and should continue to be, the cure and care for patients, and control of the results?

A last important pitfall is human nature and the pressure to comply with rules and prestige! The following examples speak for themselves. Scientists or companies falsifying data. The waiting lists fraud in the Coulchester, UK, scandal, where over 6000 data were falsified to comply with quality control. Hidden deals about reimbursement of medication recently reported in the Dutch newspaper De Telegraaf. The global mismanagement of the Veterans Affairs Department in the USA, as reported by its chief: "A systemic, totally unacceptable lack of integrity. We must be suspicious of inadequate care and clean house wherever necessary."

\section{Acknowledgments}

None.

\section{Conflicts of interest}

The authors declare there is no conflict of interests.

\section{Funding}

None.

\section{References}

1. Acheson R. The definition and identification of need for health care. Journal of Epidemiology and Community Health. 1978;32(1):10-15.

2. Obama B. Perspective: Health care reform and the presidential candidates. N Engl J Med. 2013;367:1377-1381.

3. Donabedian A. Evaluating the quality of medical care (1966). Millbank Q. 2005;83(4):691-729.

4. Morrow M, Katz S. The challenge of developing quality measures for breast cancer surgery. JAMA. 2012;307(5):509-510.

5. Roland M, Campbell S. Successes and Failures of Pay for Performance in the United Kingdom. N Engl J Med. 2014;370(20):1944-1949.

6. Research scan: Complex adaptive systems. The health foundation 2010.

7. Shear M. Veterans affairs chief resign in hospitals scandal. International New York Times; 2014. 